\title{
A CONTENT ANALYSIS OF THE HIGH-INTENSITY FUNCTIONAL TRAINING LITERATURE: A LOOK AT THE PAST AND DIRECTIONS FOR THE FUTURE
}

review paper

(c) University School of Physical Education in Wroclaw

DOI: https://doi.org/10.5114/hm.2019.81020

\section{YURI FEITO, CHRIS BROWN, ALEX OLMOS}

Department of Exercise Science and Sport Management, Kennesaw State University, Kennesaw, United States of America

\begin{abstract}
Purpose. As a form of high-intensity functional training (HIFT), CrossFit training has grown in popularity over the last decade. The aim of this analysis is to provide researchers with a tool to further guide scientific inquiry in this area of research.

Methods. Even though systematic reviews and meta-analyses are preferred when analysing and synthesizing large numbers of scientific studies, the current literature on CrossFit training is scarce. Therefore, we used a content analysis approach to (1) review the literature on the topic; (2) synthesize the available research and examine the most popular issues, trends, and methodologies used; and (3) present an overall state of the literature and propose potential directions for future research. Results. A total of 104 studies related to HIFT and CrossFit training were identified. These were published between 2007 and 2018 in 15 different countries, in 69 journals. The analysis referred to 6 main themes: (1) publication year, (2) country of research, (3) the peer-review journals publishing this type of research, (4) topical areas primarily studied, (5) research design, and (6) characteristics of individuals involved in this training modality.

Conclusions. To our knowledge, this is the first study to provide a content analysis of the available literature on HIFT and CrossFit training. The literature contributed significantly to the development of HIFT concepts, yet additional studies are needed to elucidate how HIFT/CrossFit training may differ from more traditional training programs. Hopefully, our study will facilitate collaboration among scholars interested in HIFT modalities.
\end{abstract}

Key words: fitness, reviews, exercise performance, sports

\section{Introduction}

As a form of high-intensity functional training (HIFT), CrossFit training has grown in popularity throughout the world, with the number of CrossFit gyms, or 'boxes,' increasing exponentially over the last decade and equalling over 14,000 worldwide today [1, 2]. CrossFit training began as a unique training activity, originally created by Greg Glassman in California, in the mid 1990's, and offers participants an opportunity for self-improvement and reinvention of the body and of one's identity [3, 4]. Defined as 'constantly varied functional movements performed at high intensity' [5, p. 1], CrossFit training utilizes a variety of modalities, including weight training, gymnastics, body weight movement, and mono-structural exercises, such as running, to promote general physical preparedness [5]. Along with other forms of high-intensity interval training,
HIFT and CrossFit training have become increasingly popular in the fitness community in the United States and around the globe. Initially designed as an exercise program to endorse functional fitness, CrossFit training (and, as brand, CrossFit, Inc.) has undergone an extensive transformation into a global, multi-milliondollar industry, labelling itself as the 'sport of fitness' [3, p. 363]. Although Bellar et al. [6] defined functional fitness as a form of exercise designed to emulate activities in everyday life, CrossFit ${ }^{\mathrm{TM}}$ refers to functional exercises as 'compound movements (i.e. multi-joint) requiring universal motor recruitment patterns, performed from core to extremity' [5, p. 1]. Recently, Feito et al. [7] have provided a working definition of what constitutes HIFT programs.

Periodically, it is necessary for scholars to review their field of study in terms of an overall progression of the literature [8]. Since 2007, research specifically

Correspondence address: Yuri Feito, Kennesaw State University, Department of Exercise Science and Sport Management, 520 Parliament Garden Way, NW, MD 4104 Kennesaw, GA 30144, USA, e-mail: yfeito@kennesaw.edu

Received: September 7, 2018

Accepted for publication: November 20, 2018

Citation: Feito Y, Brown C, Olmos A. A content analysis of the high-intensity functional training literature: a look at the past and directions for the future. Hum Mov. 2019;20(2):1-15; doi: https://doi.org/10.5114/hm.2019.81020. 
related to HIFT/CrossFit training has been published in a variety of journals with a wide range of topics (e.g. strength and conditioning, military medicine, sports medicine, sport behaviour, sport nutrition, sport performance). However, despite the training popularity within the fitness industry, research is scarce and studies analysing this literature are limited. To our knowledge, Knapp [9] was the first and most recent to undertake such a task when she reviewed over 2100 photographs published in the 'CrossFit Journal' and provided insight into the ideal femininity and hegemonic masculinity presented. Nonetheless, that study did not represent a comprehensive view of the available literature. Since Knapp's publication, several other investigators have offered some insight to the state of the literature, with one or two specific outcomes.

Even though systematic reviews and meta-analyses are preferred when analysing and synthesizing large numbers of scientific studies, in this case, and considering the limited research currently available, we assumed that using a content analysis strategy was the most appropriate method of achieving a meaningful outcome. Content analysis is a research technique frequently applied for examining information, or content, in written or symbolic material [10]. Many researchers have used content analysis to track trends in scholarly traditions and have identified patterns of development related to specific concepts and themes [11], which provide an unobtrusive and nonreactive measurement technique to available data [12]. Additionally, Berg and Lune [13] explained content analysis as a 'careful, detailed, systematic examination and interpretation of a particular body of material in an effort to identify patterns, themes, biases and meanings' (p. 349). For many years, researchers in comparable disciplines (e.g. hospitality, tourism, sport) have conducted this form of analysis as an instrument to determine concepts, trends, and future direction, as well as to make inferences about previous research. Considering that the goal of this article is to create a better understanding of the current literature related to HIFT and CrossFit training research, we assumed a content analysis approach as most appropriate to theorize future potential studies that would advance the literature for both scholars and practitioners. Moreover, the results of this study can be used to identify research trends and knowledge gaps, which in turn will help determine frameworks for their application in practitioner and academic development. As noted by Peetz and Reams [12], one way to examine how research in a field has been approached is through a critical examination of the literature produced. As such, investigations into the research content of a discipline can help determine what is on the cutting edge, considered valuable, or esteemed by academicians [14]. Ultimately, and considering the popularity of HIFT/ CrossFit training within the fitness industry, the scope of this study is to bring HIFT, and CrossFit training, into mainstream research.

With the growing body of research related to HIFT/ CrossFit training, a comprehensive review of the existing literature is warranted. Despite the training type popularity, no other study has attempted to summarize the available related literature in this manner. Specifically, the topical areas, the methodologies used, and the general trends in this training modality are still unclear and need particular attention. Therefore, the purpose of this research is threefold. First, we review the literature to create a baseline for current academic research specifically related to HIFT/CrossFit training and discuss topical areas and research methods in articles published in peer-reviewed journals from January 1, 2007 to October 31, 2018. Second, we synthesize the available research, emphasizing the most popular topics and trends, as well as methodologies used. Lastly, we present an overall state of the literature, discuss relevant similarities and distinctions among studies, and propose potential directions for future research.

\section{Material and methods}

As descriptive research, this study adopted the technique of content analysis to address its objectives. According to Riffe et al. [15], a content analysis involves a systematic process of collecting, categorizing, analysing, and summarizing data (usually non-numeric) into meaningful information, which allows the drawing out of valid deductions or inferences in an objective manner. For this study, given the fact that limited research of this kind has been conducted within peerreviewed journals, the specific strategies and procedures adopted were based on numerous hospitality, tourism, and sport papers that have applied content analysis [12, 16-18]. As the first step of the literature review process, the sources of data were restricted to peer-reviewed articles in exercise and sport journals. The decision to limit the data collection to journal articles was not to negate the fact that academic journals are not the only sources of HIFT/CrossFit training information, but to remain consistent with the understanding that academic journals constitute an important source of assessing current research.

The selection of the journal articles underwent 
a two-step process. In the first step, a broad search of literature related to HIFT and CrossFit training was conducted in popular online databases, namely Google Scholar and PubMed, with the use of specific keywords (e.g. CrossFit, high-intensity functional training, highintensity power training, extreme conditioning programs, intermittent training, functional exercise). Both databases are considered the most common online databases for research related to HIFT/CrossFit training. Specifically, Google Scholar has been selected in a number of other content analysis studies and is now considered a comprehensive tool for citation tracking for social science [19-22]. The keyword search was completed by members of the research team and involved listing the terms with all the sectors related to HIFT/ CrossFit training to avoid missing any relevant literature. To ensure that all applicable articles were obtained, the reference lists of the manuscripts retrieved were also checked to identify additional articles that could have been missed in the search process or were not recognized through the keywords.

In the second step, all articles were scrutinized and evaluated for meeting our inclusion criteria (i.e. fulllength peer-reviewed journal, published in English, specifically mentioning HIFT/CrossFit training or any variation thereof). Any other publications, such as research notes, case studies, editors' or readers' comments, letters to the editors, book reviews, dissertations/theses, and conference proceedings (i.e. abstracts), were not included in this analysis. In addition, each peer-reviewed article included had to be based on HIFT or CrossFit training related research (e.g. sport behaviour, motivations to participate, injuries). It was not just enough to mention CrossFit in order to be selected, but the main theme and/or concept of the paper needed to be central to HIFT/CrossFit training. Considering the lack of information in certain areas, we included several reports to provide additional content.

Subsequent to the selection of the articles, and in accordance with the purpose of the study, which was to identify emergent trends and suggestions for future research, a coding scheme for the content analysis was designed to collect a variety of categories of information appropriate for addressing the objectives of the study. The design of the scheme followed the suggestions of Marshall and Rossman [23], and Rivera and Upchurch [24]. Each article was coded on the basis of the publication year, subtopics (i.e. physiological, psychological, other), purpose/aim of the study, participant characteristics, population, research design, data collection (i.e. survey, experiment, etc.), sample size, and statistical technique.
In organizing and gathering data for the analysis, the following measures were also instituted to ensure validity and reliability. First, the codes were clarified to avoid any possible ambiguities. However, in cases where such unforeseen ambiguity arose, the issue was discussed between the researchers to reach an agreement. Second, a clear process of abstracting information, similar to that applied by Rivera and Upchurch [24] and Slattery [25], was consistently followed. For every paper, the process involved reading: (a) the entire abstract, (b) the first paragraph, (c) the first two sentences of every subsequent paragraph, and (d) the final paragraph in full. In instances where the needed information was not obtained through this selective reading, the article was read in its entirety. Lastly, after the data entry was completed, all authors of the current manuscript read through every entry to check for possible errors and make the necessary corrections, and the cleaned data were subsequently analysed.

\section{Ethical approval}

The conducted research is not related to either human or animal use.

\section{Results}

After an extensive review of the literature referencing HIFT and CrossFit training in years 2007-2018, we identified a total of 127 full-length peer-reviewed journal articles that met our inclusion criteria. After further examination for potential duplicates and reviewing the articles to make sure they specifically related to CrossFit training, we found 21 articles that, although met our inclusion criteria, did not directly study HIFT or CrossFit training, but instead were more related to high-intensity interval training. Additionally, we removed 2 specific articles as these were retracted from their respective journals during our exploratory process. Overall, at the end, we identified and collected a total of 104 studies related to HIFT/CrossFit training, published in 15 different countries and in 69 different journals between January 1, 2007 and October 31, 2018.

Below we describe 6 themes that were constructed through our research, along with several subtopics that identify trends within the compounds of CrossFit training research. The 6 main themes were as follows: (1) publication year, (2) country where the research took place, (3) the peer-review journals publishing this type of research, (4) topical areas primarily studied, (5) research design utilized, and (6) characteristics of individuals involved in this training modality. 


\section{Publication year}

Figure 1 shows the number of articles published in peer-reviewed journals through the study period. Between 2007 and 2011, a scarcity of studies was published. A technical report was published in 2010 from the Command and General Staff College of the U.S. Army, which we believe is the first instance that CrossFit training was mentioned in the literature [26]. As this type of publication was outside of the scope of this review, we mention it here, but we do not include it in our analysis. In 2011, the first peer-reviewed article mentioning CrossFit training as a form of 'extreme conditioning program' [27] was recorded. Since, the literature has seen an incremental rise in articles published, with 3 in 2012 [28-30] and in 2013 [31-33] each. In 2014, the number of publications more than doubled as compared with the previous 2 years, with a total of 7 manuscripts [34-40], and that number again doubled in 2015, with 14 articles [3, 6, 9, 41-51]. The number of papers rose to 22 in 2016 [52-73], equalled 24 in 2017 [4, 74-96], and increased to 30 at the time of this writing in October, 2018 [2, 7, 97-124]. As mentioned, as a result of some controversy surrounding several investigators [125-127], our analysis did not include 2 articles published in 2013 and in 2014, which were retracted in 2017.

We believe that the initial increase in publications after 2011 may be due in part to the major network broadcast of the 2011 CrossFit Games ${ }^{\circledR}$, which were initially transmitted by the Entertainment and Sports Programming Network (ESPN) [16]. In addition, there was also an increase in interest in the training modality as the CrossFit Games began to recruit more countries and more individuals, as it was made more appealing and open for anyone to qualify for the CrossFit Games ${ }^{\circledR}$ through the CrossFit Games Open ${ }^{\circledR}$ competition. Although there were no statistical analyses conducted to examine differences in publication numbers throughout the years, it is visually recognizable that a vast interest in research related to CrossFit training has emerged over the last decade.

\section{Research originating country}

Table 1 provides insight to the variance in publications among different countries. This review implies that studies related to CrossFit training were completed in a total of 15 countries around the world. The majority of studies were conducted in the United States (66\%), Brazil (7\%), and the United Kingdom (5\%), with Canada (4\%), and Poland and Spain (3\% each) rounding out the top five. Publications from the other 9 countries included 1 or 2 papers each in years 2007 2018. Thereby, we can see that the majority of the studies conducted over the last decade were performed in the same country where CrossFit training originated. Nonetheless, and considering the international phenomenon that CrossFit has become both as a brand and training modality over the last decade, we speculate that a greater number of studies, with more heterogeneous populations, will be carried out in the future. Moreover, we believe that as this training modality continues to grow, researchers around the world will be drawn to its appeal and will continue to produce

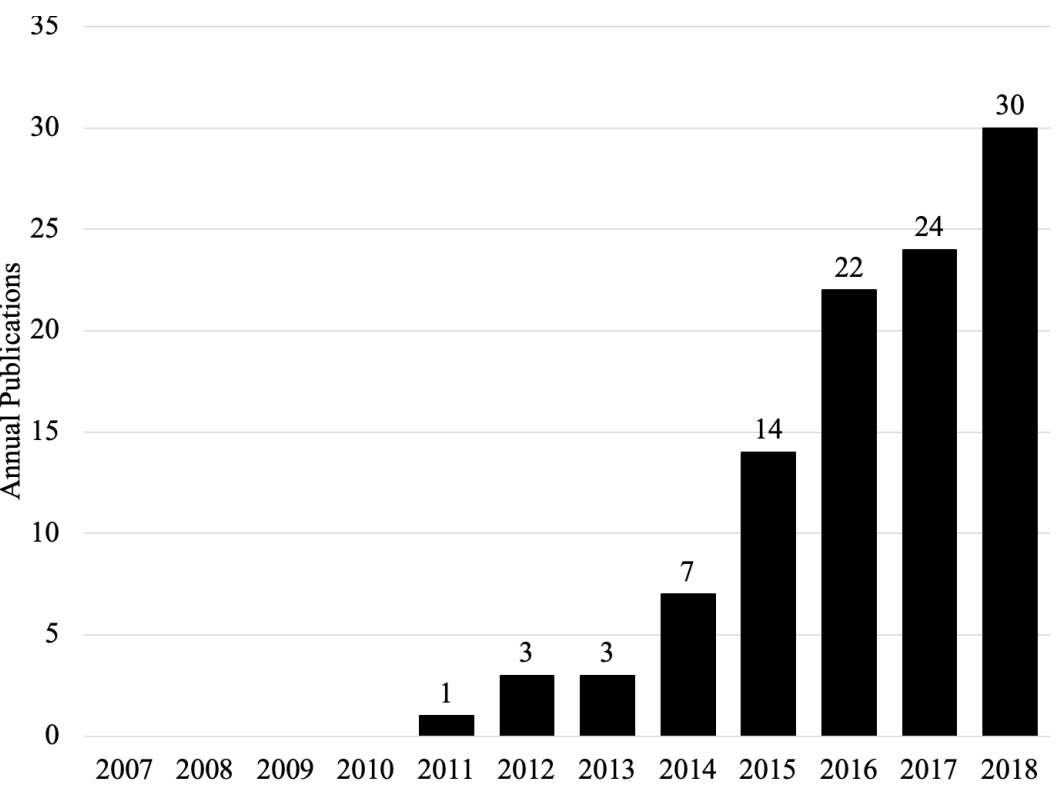

Figure 1. Number of HIFT/CrossFit training articles published in years 2007-2018 
Table 1. Countries that research related to HIFT/CrossFit training originated from in years 2007-2018

\begin{tabular}{lcc}
\hline Origin of study & $\begin{array}{c}\text { Number } \\
\text { of articles }\end{array}$ & \% of total \\
\hline United States & 69 & 66 \\
Brazil & 7 & 7 \\
United Kingdom & 5 & 5 \\
Canada & 4 & 4 \\
Poland & 3 & 3 \\
Spain & 3 & 3 \\
Italy & 2 & 2 \\
Turkey & 2 & 2 \\
Denmark & 2 & 2 \\
Australia & 2 & 2 \\
New Zealand & 1 & 1 \\
Hungary & 1 & 1 \\
Switzerland & 1 & 1 \\
Korea & 1 & 1 \\
Netherlands & 1 & 1 \\
\hline Total & 104 & 100 \\
\hline
\end{tabular}

research, which will provide additional insight to the potential benefits of CrossFit among more diverse populations.

\section{Peer-reviewed journals}

Table 2 includes the various journals that published manuscripts related to CrossFit training between 2007 and 2018. During this time, we discovered 69 different journals that published at least 1 article, with only a few with multiple manuscripts related to this training modality. Considering its aims, it is not surprising the journal of 'Sports' has the largest number of articles published: 10. This is in part the result of a special issue related to HIFT/CrossFit training, which was published in 2018. The 'Orthopaedic Journal of Sports Medicine,' 'Journal of Sports Medicine and Physical Fitness,' and 'Journal of Strength and Conditioning Research' follow with 4 publications each, and several others have 3 or 2 . Aside from the first 4 journals mentioned, it is obvious that there is a lack of publication density in any particular journal, which may be potentially suggestive of a possible editorial bias related to this type of research considering the controversy surrounding several retracted studies [126, 127]. Additionally, it seems that journals with a focus related to exercise science, conditioning, or medicine are more likely to publish this type of research. Nonetheless, we believe that this may be simply related to and driven by the topical areas of research that had been studied thus far.

\section{Topical areas}

In an attempt to improve the application of our results, we created three topical areas, which were identified from the careful interpretation of the studies included in our review (Table 3). Overall, the majority of studies $(67 \%)$ published within our study period were related to physiological parameters, where the authors were interested in examining training adaptations and physical fitness, performance, and/or injury associated with CrossFit training. Studies related to psychological parameters composed a small fraction of the papers reviewed (10\%). Because it was difficult to differentiate topic areas for some studies, we created an 'other' category, which allowed us to include studies that blended the physiological and psychological topic areas, as well as articles impossible to categorize in any of the two primary topical areas. This category included $20 \%$ of the studies reviewed. Additional information for each of the topical areas is discussed below.

\section{Physiological measures}

A total of 70 manuscripts focused on studies examining physiological variables, such as oxygen uptake $\left(\mathrm{VO}_{2}\right)$, lactate response, body composition, etc. Of the studies in this subtopic, all used quantitative designs (70 articles; 100\%) and applied experiments (49; 70\%) as their method to collect data. Surveys $(11 ; 16 \%)$, online document reviews (e.g. medical records, databases) $(5 ; 7 \%)$ or other $(5 ; 7 \%)$ completed all physiological studies. Among the variables recorded were body composition, performance measures (i.e. power output, muscular strength, cardiovascular endurance, and flexibility), and other physiological mechanisms. Overall, all reviewed studies demonstrated improvements in physiological markers, such as work capacity [26, 29], muscular strength and endurance [28, 29, 58], as well as decreases is inflammatory cytokines [72] and body weight [36, 54], among others.

One of the most frequently studied topics seen in our review was the prevalence and incidence of injuries related to HIFT. A total of 14 studies either reported collected data to calculate prevalence and incidence rates or reviewed the available literature related to HIFT and injuries [31, 32, 40, 54, 69, 74, $86,87,91,93,94,107,109,116]$. In addition, several more case studies exist describing injuries occurring within this training modality, which are not included here as they did not meet the inclusion criteria for this study. In the most comprehensive cross-sectional 


\section{HUMAN MOVEMENT}

Y. Feito, C. Brown, A. Olmos, CrossFit training: a content analysis

Table 2. Peer-review journals that published HIFT/CrossFit training related manuscripts in years 2007-2018

\begin{tabular}{|c|c|c|}
\hline Journal name & Number of studies & $\%$ of total \\
\hline Sports (Basel) & 10 & 9.6 \\
\hline Orthopaedic Journal of Sports Medicine & 4 & 3.8 \\
\hline Journal of Sports Medicine and Physical Fitness & 4 & 3.8 \\
\hline Journal of Strength and Conditioning Research & 4 & 3.8 \\
\hline Sports Health & 3 & 2.9 \\
\hline PLoS One & 3 & 2.9 \\
\hline Military Medicine & 3 & 2.9 \\
\hline Journal of Exercise Physiology Online & 3 & 2.9 \\
\hline Journal of Sport and Human Performance & 3 & 2.9 \\
\hline Women in Sport and Physical Activity Journal & 2 & 1.9 \\
\hline International Journal of Exercise Science & 2 & 1.9 \\
\hline Sports Medicine - Open & 2 & 1.9 \\
\hline Applied Physiology, Nutrition, and Metabolism & 2 & 1.9 \\
\hline International Journal of Sport, Exercise \& Training Science & 2 & 1.9 \\
\hline Journal of Human Sport and Exercise & 2 & 1.9 \\
\hline Journal of Physical Education, Recreation \& Dance & 2 & 1.9 \\
\hline European Journal of Cancer Care & 1 & 1.0 \\
\hline SpringerPlus & 1 & 1.0 \\
\hline Baylor University Medical Center Proceedings & 1 & 1.0 \\
\hline Health Behavior and Policy Review & 1 & 1.0 \\
\hline Current Sports Medicine Reports & 1 & 1.0 \\
\hline American Journal of Physiology - Endocrinology and Metabolism & 1 & 1.0 \\
\hline Orthopedic Reviews & 1 & 1.0 \\
\hline International Journal of Sport and Exercise Psychology & 1 & 1.0 \\
\hline Family \& Community Health & 1 & 1.0 \\
\hline Athletic Training and Sports Health Care & 1 & 1.0 \\
\hline Journal of Sports Science and Medicine & 1 & 1.0 \\
\hline International Journal of Sports Physiology and Performance & 1 & 1.0 \\
\hline Kinesiology & 1 & 1.0 \\
\hline International Review for the Sociology of Sport & 1 & 1.0 \\
\hline Open Access Journal of Sports Medicine & 1 & 1.0 \\
\hline Iranian Journal of Public Health & 1 & 1.0 \\
\hline The Physical Educator & 1 & 1.0 \\
\hline Journal of Consumer Culture & 1 & 1.0 \\
\hline Scandinavian Journal of Medicine \& Science in Sports & 1 & 1.0 \\
\hline Biology of Sport & 1 & 1.0 \\
\hline Sports Medicine & 1 & 1.0 \\
\hline Journal of Fitness Research & 1 & 1.0 \\
\hline Frontiers in Physiology & 1 & 1.0 \\
\hline Journal of Health Psychology & 1 & 1.0 \\
\hline Journal of Sports Sciences & 1 & 1.0 \\
\hline Journal of Human Kinetics & 1 & 1.0 \\
\hline Journal of the International Society of Sports Nutrition & 1 & 1.0 \\
\hline BMC Public Health & 1 & 1.0 \\
\hline Manual Therapy, Posturology \& Rehabilitation Journal & 1 & 1.0 \\
\hline Journal of Physical Education \& Health - Social Perspective & 1 & 1.0 \\
\hline Muscles, Ligaments and Tendons Journal & 1 & 1.0 \\
\hline Chronobiology International & 1 & 1.0 \\
\hline European Journal of Human Movement & 1 & 1.0 \\
\hline The Physician and Sportsmedicine & 1 & 1.0 \\
\hline Paragraph & 1 & 1.0 \\
\hline Workplace Health \& Safety & 1 & 1.0 \\
\hline European Journal of Physical Education and Sport Science & 1 & 1.0 \\
\hline Journal of Special Operations Medicine & 1 & 1.0 \\
\hline SAGE Open & 1 & 1.0 \\
\hline Journal of Sport and Health Science & 1 & 1.0 \\
\hline Sport in Society & 1 & 1.0 \\
\hline Clinical Journal of Sport Medicine & 1 & 1.0 \\
\hline Fashion and Textiles & 1 & 1.0 \\
\hline Journal of Sport and Social Issues & 1 & 1.0 \\
\hline Fisioterapia e Pesquisa & 1 & 1.0 \\
\hline Journal of Sport Behavior & 1 & 1.0 \\
\hline U.S. Army Medical Department Journal & 1 & 1.0 \\
\hline Journal of Sport Rehabilitation & 1 & 1.0 \\
\hline Communication \& Sport & 1 & 1.0 \\
\hline Journal of Physiology and Pharmacology & 1 & 1.0 \\
\hline Addictive Behaviors Reports & 1 & 1.0 \\
\hline Journal of Science and Medicine in Sport & 1 & 1.0 \\
\hline Sport Journal & 1 & 1.0 \\
\hline Total & 104 & 100.0 \\
\hline
\end{tabular}


Table 3. The study topical areas, research design, and data collection methods

\begin{tabular}{|c|c|c|c|c|c|c|c|}
\hline \multirow{2}{*}{ Topic area } & \multicolumn{7}{|c|}{ Data collection methods } \\
\hline & Research design & Experiment & Interview focused & Survey & Online document & Other & Total \\
\hline \multicolumn{8}{|c|}{ Physiological } \\
\hline & Quantitative & 49 & & 11 & 5 & 5 & 70 \\
\hline & Qualitative & & & & & & \\
\hline & Other & & & & & & \\
\hline & Mixed & & & & & & \\
\hline \multicolumn{8}{|c|}{ Psychological } \\
\hline & Quantitative & 5 & & 6 & & & 11 \\
\hline & Qualitative & & 2 & & & & 2 \\
\hline & Other & & & & & & \\
\hline & Mixed & & & & & & \\
\hline \multicolumn{8}{|l|}{ Other } \\
\hline & Quantitative & & & 3 & 2 & 4 & 9 \\
\hline & Qualitative & & & & & 8 & 8 \\
\hline & Other & & & 1 & & 3 & 4 \\
\hline & Mixed & & & & & & \\
\hline Total & & 54 & 2 & 21 & 7 & 20 & 104 \\
\hline
\end{tabular}

study, Feito et al. [109] assessed the incidence of injuries among over 3000 CrossFit participants from around the world over a 4-year period. The researchers conclude that CrossFit training 'seems to be a safe exercise program that has provided an avenue for thousands of people around the world to become physically active' (p. 5). Moreover, the authors suggested that males were more likely to report an injury than females, and those engaging in the modality less than 3 days per week and with less than 1 year of experience were at greatest risks of reporting an injury. In summary, the currently available evidence supports Feito et al.'s claim that CrossFit training is relatively safe; the injury rates, ranging between 2 and 3 injuries per 1000 hours of training [32, 40, 69, 87, 91, 103], are similar to traditional training programs.

\section{Psychological measures}

The psychological subtopic was represented by studies that focused on psychological measures, such as enjoyment, adherence, autonomy, etc. A total of 13 (13\%) articles were included in this subtopic, and the majority used quantitative designs (11 articles; 84\%), with surveys (6 articles; $60 \%$ ) being the main method of collecting data. General themes consisted of adherence, environment, and body image. Heinrich et al. [36] compared a CrossFit training-based program with aerobic/resistance training (ART) and even though body composition changes were not observed, those who engaged in the CrossFit training program spent significantly less time exercising per week, while demonstrating greater enjoyment, and were more likely to continue with the exercise program than those in the ART group. Similarly, Dawson [3] postulated that CrossFit training provided an opportunity for self-improvement and reinvention of one's body, while maintaining a sense of autonomy. Meanwhile, Davies et al. [56] explored the issue of need satisfaction among CrossFit training participants and demonstrated that those who attended more frequently had significantly higher levels of basic need satisfaction across all three needs (e.g. autonomy, relatedness, and competence). The authors reported that these three basic needs explained over $38 \%$ of the variance in autonomous regulation, which provided the first empirical evidence of the connections between basic psychological need satisfaction and self-determined regulation toward CrossFit training.

Whiteman-Sandland et al. [2] examined the role of social capital and community among CrossFit participants and demonstrated that those engaged in CrossFit training were more likely to bond with others and had a greater sense of community belongingness compared with more traditional gym members. Nonetheless, the authors were unable to show that this sense of belongingness was a significant predictor of attendance, suggesting that social capital and community belongingness did not increase adherence among their study participants. Fisher et al. [83] posited that the motives 
to engage in CrossFit training might be similar to those seen in sport participation, and thus facilitated long-term adherence compared with other resistance training programs. Their findings provided additional evidence that those engaged in CrossFit training were more apt to be motivated by intrinsic factors, such as enjoyment, challenge, and affiliation, while those engaged in more traditional training programs were more driven by health-related motives, such as positive health, ill-health avoidance, and weight management. Similarly, Feito et al. [112] explored participant's motives to engage in CrossFit training on the basis of their training frequency. Overall, these authors reported significantly higher intrinsic motivation (i.e. enjoyment, challenge, affiliation, etc.) among those who trained more frequently, whereas those training less frequently were more extrinsically motivated. Additionally, Box et al. [100] investigated how mood changed throughout 5 weeks of an online competition and with each successive workout. They showed that consecutive weeks of performing at the competition level did not significantly alter mood prior to the competition workouts [100].

\section{Other measures}

This subtopic consisted of 21 studies [2, 7, 9, 27, 30, $33,48-50,67,72,73,75,85,90,98,114,118,120]$ that looked at a variety of topics related to HIFT/CrossFit training, which could not be classified as either physiological or psychological. The majority of these articles utilized a quantitative design (9 articles; 43\%). Some of the themes in this subtopic included the use of CrossFit training as an educational tool, gender issues related to this training modality, as well as a look at CrossFit coaches' demographics and the use of CrossFit training in the classroom as a teaching tool. Sibley [30] explained how this training modality could be implemented within a physical education curriculum among high school students. The purpose of this article was more pedagogical in nature and did not involve any hypothesis testing; it explained how the authors had incorporated the parts of this training program into a course. In 2015, Knapp [9] applied a content analysis approach to examine the amount of visual coverage between male and female athletes within the 'CrossFit Journal'. After reviewing over 2100 photographs, the author concluded that even though males seemed to have greater representation in the 'CrossFit Journal,' gender inclusivity continued to increase with more female athletes being highlight as strong and powerful athletes. Waryasz et al. [72] and Max- well et al. [90] provided insight to the level of education among a group of CrossFit coaches as related to exercise programming and nutrition, respectively.

\section{Research design}

We also examined the research methodologies of each study to examine the heterogeneity of research designs. On the basis of our review and in line with the hospitality and tourism discipline, which we used as the basis for this study, we found that research related to CrossFit training tended to be empirical in nature, with the vast majority of articles using quantitative research designs (87\%) (Table 3). In terms of data collection, experimental research design was the most prevalent with $52 \%$ of studies, followed by survey methods (20\%). We created a category of 'other' for those studies in which the authors did not provide insight to the type of tool used to collect data or used other methodological approaches that did not fit the categories that the authors of the present study created (i.e. images); a total of 21 studies (19\%) fit this category. Of the studies reviewed, 7 (7\%) utilized online documents (i.e. online databases, medical records) and 1 study [122] used interviews to examine the factors that promoted participation in CrossFit training among pregnant women. Because of the nature of CrossFit training, it makes sense that experimental designs are most common.

Taking a closer look at study designs, we saw that the majority of studies were cross-sectional in nature (61\%), followed by reviews (12\%), and longitudinal study designs (11\%) (Table 4). Most studies dealt with

Table 4. Study design and follow-up duration

\begin{tabular}{lcc}
\hline Characteristics & Number of studies & \% of total \\
\hline Cross-sectional & 63 & 61 \\
Review & 12 & 12 \\
Thematic & 8 & 8 \\
Educational & 4 & 4 \\
Theory & 4 & 4 \\
Content analysis & 1 & 1 \\
Longitudinal & 11 & 11 \\
Descriptive review & 1 & 1 \\
5 weeks & 1 & 1 \\
6 weeks & 2 & 2 \\
8 weeks & 3 & 3 \\
9 weeks & 1 & 1 \\
12 weeks & 3 & 3 \\
16 weeks & 1 & 1 \\
\hline Total & 104 & 100 \\
\hline
\end{tabular}


injury incidence. Of those that included review methodologies, only 1 provided a meta-analysis approach [103]; however, the interpretation of the meta-analysis related to benefits or risks of HIFT/CrossFit training was inconclusive as a small number of studies were included in the analysis. Further studies of this nature should be conducted to accurately assess the potential benefits and risks of this training modality.

Overall, 11 studies included longitudinal designs to evaluate a number of physiological and psychological variables. Studies were designed to follow participants anywhere between 5 and 16 weeks, with the vast majority applying an 8- or 12-week follow-up. Feito et al. [111] conducted the longest study available at the time of this writing. However, of the 53 participants enrolled, only 26 completed post-testing, which resulted in nearly a 50\% drop-out rate. Even though this dropout rate is not uncommon in unsupervised environments [128], it provides insight to the difficulty of keeping participants enrolled in this type of longitudinal studies. Albeit these results, Heinrich et al. $[36,45]$, in two independent studies, reported $75 \%$ adherence to a HIFT program among overweight/obese individuals (8 weeks) and cancer patients (5 weeks). Lastly, Carnes et al. [101] were able to achieve $80 \%$ adherence to their 12-week comparison of training modes. However, unlike in the studies by Feito et al. [111] and Heinrich et al. [36, 45], these participants were recreational distance runners, who had covered more than $16 \mathrm{~km}$ per week for the previous 3 months, which may limit comparisons regarding participation, as these individuals had already been exercising prior to enrolment. Nonetheless, the findings from Heinrich et al. [36, 45] are encouraging as more and more individuals struggle to meet exercise guidelines.

\section{Discussion}

Over the last decade, CrossFit training has developed a comfortable niche within the fitness industry, and has differentiated its own position and audience from other types of training modalities. The increase in participation and overall interest has highlighted a significant growth in research, and has provided additional needs for future research within the field. Considering the rise in popularity of CrossFit training over the last decade, both as a worldwide brand and a training program, the aims of this content analysis were to (1) examine the current state of the literature related to this training modality, (2) synthesize the available research emphasizing the most popular topics and trends, and (3) discuss relevant similarities and distinctions among studies, as well as propose potential directions for future research.

Forming a clear picture of the research state of a certain topic requires periodical monitoring of its progress [24]. Therefore, the present study provides valuable contributions to the research literature in several ways. To our knowledge, and on the basis of our findings, this is the first study to provide a comprehensive review of the current literature and draw a big picture of research related to HIFT/CrossFit training over the last decade. Although several studies have focused on the physiological and psychological impact of HIFT/CrossFit training, and several systematic reviews exist, no other study has investigated the research concepts and trends related specifically to this training modality. As CrossFit training continues to gain popularity among exercisers and practitioners, scholars have a need to continue to gain additional insights from this unique research area. Moreover, we believe that this work has created a roadmap related to the emerging trends specific to this training modality to be applied in future research.

The findings of the current study show that although HIFT/CrossFit training has gained significant popularity within the fitness industry, limited progress has been made in researching this modality over the last decade, which reveals a need for continued efforts to be made to improve the width and breadth of this area of research. As an optimistic analysis of the literature, this content analysis shows that HIFT/CrossFit training research is in its infancy with a total of 104 full-length, peer-reviewed research articles among 69 different journals. To put this in perspective, a quick look at the term 'high-intensity interval training' in PubMed $^{\circledR}$ (pubmed.gov) yielded over 1700 studies during the time frame covered by this content analysis. Again, suggesting that although the research related to HIFT/CrossFit training has increased, it is still only a fraction of other research in a similar area. It is logical that most studies focus on physiological parameters but there remains a need for current and future researchers to expand the scope of their investigation to allow for a deeper understanding of HIFT/CrossFit training. More specifically, most of the physiological studies reviewed use small sample sizes to draw conclusions so there is a need for randomized control trials that would provide comparisons with other types of training modalities (i.e. high-intensity interval training) to accurately determine the effectiveness of these types of programs. Additionally, there is a necessity to include clinical populations in future studies to assess the effectiveness of this type of training modality in other 
populations. Also, it is important to better understand the role of this training modality in exercise adherence promotion as physical inactivity continues to be a significant risk factor for many chronic conditions in the US [129] and around the globe [130].

The results of the present investigation suggest that scholars and professionals interested in this type of training modality have limited peer-reviewed research to focus on, and future research in the area could have a significant impact to advance the field. This study provides empirical evidence that the field of HIFT modalities and, more specifically, CrossFit training, is falling short of providing literature representative of the exponential growth of this specific training modality. While some good work has been completed, there is definitely additional effort that should be taken to better understand how CrossFit training may be different from other training modalities, elucidate the acute and potential chronic adaptations to this type of training, as well as determine how this type of training my impact an individual's behaviour related to physical activity and exercise. While it is not the intent of this article to focus on why HIFT/CrossFit training research is poorly represented within the literature, it is clear that additional studies are needed to increase research productivity in this area. An argument can be made that academics and journal editors are fearful of conducting and publishing this type of research, considering the controversy related to several publications [126, 127]; however, authors should bear the responsibility to conduct all studies within the ethical purviews of academic writing [131] and editors should maintain standards that would provide accountability for further investigation that would shape the future of HIFT-related research. The authors are hopeful that this study will serve as a facilitator to encourage academicians in the field of exercise science, performance, and kinesiology overall to conduct additional research with a focus on HIFT/CrossFit training. Taking into account its growth in popularity over the last decade and the documented physiological and psychological effects of participating in this training modality, along with the trillions spent annually in health care cost related to chronic and mental health [132], it is important to highlight training modalities that provide significant physiological and psychological benefits, as well as promote exercise adherence in order to engage more individuals in an active lifestyle.

Although we have attempted to conduct this research with the greatest level of accuracy, it is not exempt from limitations. Primarily, we were interested in examining literature related to HIFT/CrossFit training; thus, our research did not include other training modalities, such as high-intensity interval training, or other functional style types of training. As such, the classifications and trends created in the study may not be generalizable to all other high-intensity modalities. Future research should include these other modalities and delineate a great scope of this type of training.

\section{Conclusions}

On a practical level, this study identified research topics and methods used to investigate this relatively new type of exercise training in order to facilitate collaborations among scholars and practitioners interested in HIFT modalities to create new lines of research in this area. These collaborations have the potential to not only enhance the knowledge base in the field, but also facilitate both qualitative and quantitative research related to CrossFit training as it currently appears disjointed and unrelated. Therefore, as this training modality continues to grow, we would recommend the development of a model or an agenda for research to guide scholars, practitioners, and researchers in addressing gaps of research within HIFT modalities, specifically CrossFit training.

Overall, this study identifies the current state of research related to HIFT/CrossFit training over the last decade and offers a catalyst to move forward with the aim of advancing the body of literature unique to this training modality. Undeniably, there is no shortage of possible future research topics for all subfields within the discipline. To date, this research has made significant contributions in the development, articulation, improvement, and synthesis of HIFT concepts, yet additional studies are needed to elucidate how HIFT/ CrossFit training may differ from other, more traditional training programs. Nonetheless, it important to note the necessary divergence from the term 'extreme conditioning training' that was first given to this type of training in 2011 [27]. The current evidence no longer supports the classification of 'extreme' for this type of training, as several studies [42, 43, 47] have demonstrated that the intensities typically used in this type of training are within the established exercise prescription guidelines set forth by the American College of Sports Medicine [133]. As such, HIFT/CrossFit training does not have to be any more 'extreme' than traditional high-intensity interval training protocols.

\section{Acknowledgments}

The authors would like to recognize Ms. Maria A. Micalizzi, Ms. Ashton Matson, Mr. Jacob McNabb, 
Mr. Taylor Boyett, and Mr. Navin Khan, who aided with data collection.

\section{Funding}

This study was not supported by any external grant mechanisms or sources.

\section{Disclosure statement}

No author has any financial interest or received any financial benefit from this research.

\section{Conflict of interest}

The authors state no conflict of interest.

\section{References}

1. Ritter E. Why CrossFit brands should aggregate reviews to maintain growth. 2014. Available from: http:// www.channelsignal.com/fresh-signals/by-the-numbers-the-growth-of-crossfit.

2. Whiteman-Sandland J, Hawkins J, Clayton D. The role of social capital and community belongingness for exercise adherence: an exploratory study of the CrossFit gym model. J Health Psychol. 2018;23(12):1545-1556; doi: 10.1177/1359105316664132.

3. Dawson MC. CrossFit: fitness cult or reinventive institution? Int Rev Sociol Sport. 2015;52(3):361-379; doi: 10.1177/1012690215591793.

4. Simpson D, Prewitt-White TR, Feito Y, Giusti J, Shuda R. Challenge, commitment, community, and empowerment: factors that promote the adoption of CrossFit as a training program. Sport J. 2017;2017:1-14.

5. Glassman G. Understanding CrossFit. CrossFit J. 2007; $56: 1-2$.

6. Bellar D, Hatchett A, Judge LW, Breaux ME, Marcus L. The relationship of aerobic capacity, anaerobic peak power and experience to performance in CrossFit exercise. Biol Sport. 2015;32(4):315-320; doi: 10.5604/ 20831862.1174771.

7. Feito Y, Heinrich KM, Butcher SJ, Poston WSC. Highintensity functional training (HIFT): definition and research implications for improved fitness. Sports. 2018; 6(3); doi: 10.3390/sports6030076.

8. Line ND, Runyan RC. Hospitality marketing research: recent trends and future directions. Int J Hospit Manag. 2012;31(2):477-488; doi: 10.1016/j.ijhm.2011.07.006.

9. Knapp BA. Gender representation in the CrossFit Journal: a content analysis. Sport Soc. 2015;18(6):688-703; doi: 10.1080/17430437.2014.982544.

10. Neuman LW. Social research methods: qualitative and quantitative approaches, $7^{\text {th }}$ ed. Harlow: Pearson Education Limited; 2014.

11. Lu J, Nepal SK. Sustainable tourism research: an analysis of papers published in the Journal of Sustainable Tourism. J Sustain Tourism. 2009;17(1):5-16; doi: 10.1080/09669580802582480.
12. Peetz TB, Reams L. A content analysis of sport marketing quarterly: 1992-2011. Sport Marketing Quarter. 2011;20(4):209-218.

13. Berg BL, Lune H. Qualitative research methods for the social sciences, $8^{\text {th }}$ ed. Boston: Pearson; 2012.

14. Pedersen PM, Pitts B. Investigating the body of knowledge in sport management: a content analysis of the Sport Marketing Quarterly. Chron Phys Educ High Educ. 2001;12(3):8-9, 22-23.

15. Riffe D, Lacy S, Fico FG. Analyzing media messages: using quantitative content analysis in research, $2^{\text {nd }} \mathrm{ed}$. Mahwah: Lawrence Erlbaum Associates; 2005.

16. Imbo W. ESPN \& the CrossFit Games: how it all started \& what it means now. Boxlife. July 2015. Available from: https://boxlifemagazine.com/espn-the-crossfit-gameshow-it-all-started-what-it-means-now-the-2015-tvschedule/.

17. Mohammed I, Guillet BD, Law R. The contributions of economics to hospitality literature: a content analysis of hospitality and tourism journals. Int J Hospit Manag. 2015;44:99-110; doi: 10.1016/j.ijhm.2014.10.010.

18. Riffe D, Lacy S, Fico F. Analyzing media messages: using quantitative content analysis in research, $3^{\text {rd }}$ ed. New York: Routledge; 2014.

19. Kousha K, Thelwall M. Google Scholar citations and Google Web/URL citations: a multi-discipline exploratoryanalysis.JAssocInfSciTechnol.2007;58(7):10551065; doi: 10.1002/asi.20584.

20. Xiao H, Smith SLJ. Knowledge impact an appraisal of tourism scholarship. Ann Tourism Res. 2008;35(1):6283; doi: 10.1016/j.annals.2007.06.008.

21. Banyai M, Glover TD. Evaluating research methods on travel blogs. J Travel Res. 2012;51(3):267-277; doi: 10.1177/0047287511410323.

22. Griffin T. Research note: a content analysis of articles on visiting friends and relatives tourism, 1990-2010. J Hospit Market Manag. 2013;22(7):781-802; doi: 10.1080/19368623.2012.708960.

23. Marshall C, Rossman GB. Designing qualitative research, $4^{\text {th }}$ ed. Thousand Oaks: Sage Publications; 2011.

24. Rivera MA, Upchurch R. The role of research in the hospitality industry: a content analysis of the IJHM between 2000 and 2005. Int J Hospit Manag. 2008; 27(4):632-640; doi: 10.1016/j.ijhm.2007.08.008.

25. Slattery P. Finding the hospitality industry. J Hospit Leisure Sport Tourism Educ. 2002;1(1):19-28; doi: 10.3794/johlste.11.7.

26. Paine J, Uptgraft J, Wylie R. CGSC CrossFit study. May 2010. Available from: http://www.dtic.mil/dtic/ tr/fulltext/u2/a560056.pdf.

27. Bergeron MF, Nindl BC, Deuster PA, Baumgartner N, Kane SF, Kraemer WJ, et al. Consortium for Health and Military Performance and American College of Sports Medicine consensus paper on extreme conditioning programs in military personnel. Curr Sports Med Rep. 2011;10(6):383-389; doi: 10.1249/JSR.0b013e 318237bf8a. 
28. Barfield JP, Channell B, Pugh C, Tuck M, Pendel D. Format of basic instruction program resistance training classes: effect on fitness change in college students. Phys Educator. 2012;69(4):325-341.

29. Heinrich KM, Spencer V, Fehl N, Poston WS. Mission essential fitness: comparison of functional circuit training to traditional Army physical training for active duty military. Mil Med. 2012;177(10):1125-1130; doi: 10.7205/MILMED-D-12-00143.

30. Sibley BA. Using sport education to implement a CrossFit unit. J Phys Educ Recreat Dance. 2012;83(8):42-48; doi: 10.1080/07303084.2012.10598829.

31. Grier T, Canham-Chervak M, McNulty V, Jones BH. Extreme conditioning programs and injury risk in a US Army Brigade Combat Team. US Army Med Dep J. 2013;Oct-Dec:36-47.

32. Hak PT, Hodzovic E, Hickey B. The nature and prevalence of injury during CrossFit training. J Strength Cond Res. 2013; doi: 10.1519/JSC.0000000000000318.

33. Kozub FM. Using the snatch and CrossFit principles to facilitate fitness. Konukman F (ed.). J Phys Educ RecreatDance. 2013;84(6):13-16; doi: 10.1080/07303084. 2013.808121.

34. Barfield JP, Anderson A. Effect of CrossFit ${ }^{\mathrm{TM}}$ on health-related physical fitness: a pilot study. J Sport Hum Perf. 2014;2(1); doi: 10.12922/jshp.0033.2014.

35. Brupbacher G, Harder J, Faude O, Zahner L, Donath L. Music in CrossFit - influence on performance, physiological, and psychological parameters. Sports. 2014;2(1): 14-23; doi: 10.3390/sports2010014.

36. Heinrich KM, Patel PM, O’Neal JL, Heinrich BS. High-intensity compared to moderate-intensity training for exercise initiation, enjoyment, adherence, and intentions: an intervention study. BMC Public Health. 2014;14(1):789; doi: 10.1186/1471-2458-14-789.

37. Kliszczewicz B, Snarr RL, Esco M. Metabolic and cardiovascular response to the CrossFit workout 'Cindy': a pilot study. J Sport Hum Perf. 2014;2(2):1-9; doi: 10.12922/jshp.0038.2014.

38. Outlaw JJ, Wilborn CD, Smith-Ryan AE, Hayward SE, Urbina SL, Taylor LW, et al. Effects of a pre- and postworkout protein-carbohydrate supplement in trained CrossFit individuals. Springerplus. 2014;3(1):369; doi: 10.1186/2193-1801-3-369.

39. Partridge JA, Knapp BA, Massengale BD. An investigation of motivational variables in CrossFit facilities. J Strength Cond Res. 2014;28(6):1714-1721; doi: 10.1519/ JSC.0000000000000288.

40. Weisenthal BM, Beck CA, Maloney MD, DeHaven KE, Giordano BD. Injury rate and patterns among CrossFit athletes. Orthop J Sports Med. 2014;2(4):232596711 4531177; doi: 10.1177/2325967114531177.

41. Buckley S, Knapp K, Lackie A, Lewry C, Horvey K, Benko C, et al. Multimodal high-intensity interval training increases muscle function and metabolic performance in females. Appl Physiol Nutr Metab. 2015; 40(11):1157-1162; doi: 10.1139/apnm-2015-0238.
42. Butcher SJ, Judd TB, Benko CR, Horvey KJ, Pshyk AD. Relative intensity of two types of CrossFit exercise: acute circuit and high-intensity interval exercise. J Fitness Res. 2015;4(2):3-15.

43. Butcher SJ, Neyedly TJ, Horvey KJ, Benko CR. Do physiological measures predict selected CrossFit ${ }^{\circledR}$ benchmark performance? Open Access J Sports Med. 2015; 6:241-247; doi: 10.2147/OAJSM.S88265.

44. Fernández JF, Solana RS, Moya D, Marin JMS, Ramón MM. Acute physiological responses during CrossFit ${ }^{\circledR}$ workouts. Eur J Hum Mov. 2015;35:114-124.

45. Heinrich KM, Becker C, Carlisle T, Gilmore K, Hauser J, Frye J, et al. High-intensity functional training improves functional movement and body composition among cancer survivors: a pilot study. Eur J Cancer Care. 2015;24(6):812-817; doi: 10.1111/ecc.12338.

46. Heywood L. The CrossFit sensorium: visuality, affect and immersive sport. Paragraph. 2015;38(1):20-36; doi: 10.3366/para.2015.0144.

47. Kliszczewicz B, Quindry CJ, Blessing LD, Oliver GD, Esco RM, Taylor JK. Acute exercise and oxidative stress: CrossFit $^{\mathrm{TM}}$ vs. treadmill bout. J Hum Kinet. 2015;47(1): 81-90; doi: 10.1515/hukin-2015-0064.

48. Knapik JJ. Extreme conditioning programs: potential benefits and potential risks. J Spec Oper Med. 2015; 15(3):108-113.

49. Knapp BA. Rx'd and shirtless: an examination of gender in a CrossFit box. Women Sport Phys Act J. 2015;23(1): 42-53; doi: 10.1123/wspaj.2014-0021.

50. Mullins N. CrossFit: remember what you have learned; apply what you know. J Exerc Physiol Online. 2015; 18(6):32-44.

51. Murawska-Cialowicz E, Wojna J, Zuwala-Jagiello J. CrossFit training changes brain-derived neurotrophic factor and irisin levels at rest, after wingate and progressive tests, and improves aerobic capacity and body composition of young physically active men and women. J Physiol Pharmacol. 2015;66(6):811-821.

52. Kliszczewicz BM, Esco MR, Quindry JC, Blessing DL, Oliver GD, Taylor KJ, et al. Autonomic responses to an acute bout of high-intensity body weight resistance exercise vs. treadmill running. J Strength Cond Res. 2016;30(4):1050-1058; doi: 10.1519/JSC.000000000 0001173.

53. Baștuğ G, Özcan R, Gültekin D, Günay Ö. The effects of cross-fit, Pilates and Zumba exercise on body composition and body image of women. Int J Sports Exerc Train Sci. 2016;2(1):22-29; doi: 10.18826/ijsets.25037.

54. Chachula LA, Cameron KL, Svoboda SJ. Association of prior injury with the report of new injuries sustained during CrossFit training. Athl Train Sports Health Care. 2016;8(1):28-34; doi: 10.3928/19425864-20151119-02.

55. Cronin CC, Miller BL, Simpson JD, Boman SM, Green JM, Helm Allen JA, et al. Natural training hydration status, sweat rates, and perception of sweat losses during CrossFit training. Int J Exerc Sci. 2016;9(5):576-586. 
56. Davies MJ, Coleman L, Stellino MB. The relationship between basic psychological need satisfaction, behavioral regulation, and participation in CrossFit. J Sport Behavior. 2016;39(3):239-254.

57. De Sousa AFM, dos Santos GB, dos Reis T, Valerino AJR, Del Rosso S, Boullosa DA. Differences in physical fitness between recreational CrossFit ${ }^{\circledR}$ and resistance trained individuals. J Exerc Physiol Online. 2016; 19(5):112-122.

58. Drum SN, Bellovary BN, Jensen RL, Moore MT, Donath L. Perceived demands and postexercise physical dysfunction in CrossFit ${ }^{\circledR}$ compared to an ACSM based training session. J Sports Med Phys Fitness. 2017;57(5): 604-609; doi: 10.23736/S0022-4707.16.06243-5.

59. Eather N, Morgan PJ, Lubans DR. Improving healthrelated fitness in adolescents: the CrossFit Teens ${ }^{\mathrm{TM}}$ randomised controlled trial. J Sports Sci. 2016;34(3):209_ 223; doi: 10.1080/02640414.2015.1045925.

60. Escobar KA, Morales J, Vandusseldorp TA. The effect of a moderately low and high carbohydrate intake on CrossFit performance. Int J Exerc Sci. 2016;9(3):460470.

61. Haddock CK, Poston WS, Heinrich KM, Jahnke SA, Jitnarin N. The benefits of high-intensity functional training fitness programs for military personnel. Mil Med. 2016;181(11):e1508-e1514; doi: 10.7205/ MILMED-D-15-00503.

62. Kliszczewicz B, Feito Y, Bycura D, Brown D, Price B. Vagal response to 15-weeks of high-intensity functional training: a pilot study. J Sport Hum Perf. 2016;4(3):1-10; doi: 10.12922/jshp.v4i3.90.

63. Köteles F, Kollsete M, Kollsete H. Psychological concomitants of CrossFit training: does more exercise really make your everyday psychological functioning better? Kinesiology. 2016;48(1):39-48; doi: 10.26582/k.48.1.13.

64. Kramer SJ, Baur DA, Spicer MT, Vukovich MD, Ormsbee MJ. The effect of six days of dietary nitrate supplementation on performance in trained CrossFit athletes. J Int Soc Sports Nutr. 2016;13(1):39; doi: 10.1186/s12970-016-0150-y.

65. Lichtenstein MB, Jensen TT. Exercise addiction in CrossFit: prevalence and psychometric properties of the Exercise Addiction Inventory. Addict Behav Rep. 2016;3:33-37; doi: 10.1016/j.abrep.2016.02.002.

66. Perciavalle V, Marchetta NS, Giustiniani S, Borbone C, Perciavalle V, Petralia MC, et al. Attentive processes, blood lactate and CrossFit ${ }^{\circledR}$. Phys Sportsmed. 2016;44(4): 403-406; doi: 10.1080/00913847.2016.1222852.

67. Poston WS, Haddock CK, Heinrich KM, Jahnke SA, Jitnarin N, Batchelor DB. Is high-intensity functional training (HIFT)/CrossFit safe for military fitness training? Mil Med. 2016;181(7):627-637; doi: 10.7205/ MILMED-D-15-00273.

68. Sprey JW, Ferreira T, de Lima MV, Duarte A Jr, Jorge PB, Santili C. An epidemiological profile of CrossFit athletes in Brazil. Orthop J Sports Med. 2016;4(8):2325 967116663706; doi: 10.1177/2325967116663706.
69. Summitt RJ, Cotton RA, Kays AC, Slaven EJ. Shoulder injuries in individuals who participate in CrossFit training. Sports Health. 2016;8(6):541-546; doi: $10.1177 / 1941738116666073$.

70. Tafuri S, Notarnicola A, Monno A, Ferretti F, Moretti B. CrossFit athletes exhibit high symmetry of fundamental movement patterns. A cross-sectional study. Muscles Ligaments Tendons J. 2016;6(1):157-160; doi: 10.11138/mltj/2016.6.1.157.

71. Tibana RA, de Almeida LM, Frade de Sousa NM, Nascimento DD, Neto IV, de Almeida JA, de Souza VC, Lopes MD, Nobrega OD, Vieira DC, Navalta JW. Two consecutive days of CrossFit training affects pro and anti-inflammatory cytokines and osteoprotegerin without impairments in muscle power. Frontiers in physiology. 2016 Jun 28;7:260; doi: 10.3389/fphys. 2016.00260.

72. Waryasz GR, Suric V, Daniels AH, Gil JA, Eberson CP. CrossFit ${ }^{\circledR}$ instructor demographics and practice trends. Orthopedic reviews. 2016 Nov 17;8(4); doi: 10.4081/ or.2016.6571.

73. Washington MS, Economides M. Strong is the new sexy: Women, crossfit, and the postfeminist ideal. Journal of Sport and Social Issues. 2016;40(2):143-61; doi: $10.1177 / 0193723515615181$.

74. Aune KT, Powers JM. Injuries in an extreme conditioning program. Sports Health. 2017;9(1):52-58; doi: $10.1177 / 1941738116674895$.

75. Powers D, Greenwell DM. Branded fitness: exercise and promotional culture. J Consum Cult. 2017;17(3): 523-541; doi: 10.1177/1469540515623606.

76. Barbieri JF, Correia RF, Castaño LAA, Brasil DVC, Ribeiro AN. Comparative and correlational analysis of the performance from 2016 CrossFit games highlevel athletes. Man Ther Posturology Rehabil J. 2017; 15:521; doi: 10.17784/mtprehabjournal.2017.15.521.

77. Borras PA, Herrera J, Ponseti FJ. Effects of CrossFit lessons in physical education on the aerobic capacity of young students. J Phys Educ Health Social Perspective. 2017;6(10):5-11.

78. Burr JF, Beck JL, Durocher JJ. The relationship of high-intensity cross-training with arterial stiffness. J SportHealth Sci. 2017; doi: 10.1016/j.jshs.2017.01.009.

79. Bycura D, Feito Y, Prather C. Motivational factors in CrossFit ${ }^{\circledR}$ training participation. Health Behav Policy Rev. 2017;4(6):539-550; doi: 10.14485/HBPR.4.6.4.

80. Drake N, Smeed J, Carper MJ, Crawford DA. Effects of short-term CrossFit ${ }^{\mathrm{TM}}$ training: a magnitude-based approach. J Exerc Physiol Online. 2017;20(2):111-133.

81. Escobar KA, Morales J, VanDusseldorp TA. Metabolic profile of a CrossFit training bout. J Hum Sport Exerc. 2017;12(4):1248-1255; doi: 10.14198/jhse.2017.124.11.

82. Choi EJ, So WY, Jeong TT. Effects of the CrossFit exercise data analysis on body composition and blood profiles. Iran J Public Health. 2017;46(9):1292-1294.

83. Fisher J, Sales A, Carlson L, Steele J. A comparison of the motivational factors between CrossFit participants 
and other resistance exercise modalities: a pilot study. J Sports Med Phys Fitness. 2017;57(9):1227-1234; doi: 10.23736/S0022-4707.16.06434-3.

84. Fisker F, Kildegaard S, Thygesen M, Grosen K, PfeifferJensen M. Acute tendon changes in intense CrossFit workout: an observational cohort study. Scand J Med Sci Sports. 2017;27(11):1258-1262; doi: 10.1111/sms. 12781.

85. Heinrich KM, Carlisle T, Kehler A, Cosgrove SJ. Mapping coaches' views of participation in CrossFit to the integrated theory of health behavior change and sense of community. Fam Community Health. 2017;40(1): 24-27; doi: 10.1097/FCH.0000000000000133.

86. Hopkins BS, Cloney MB, Kesavabhotla K, Yamaguchi J, Smith ZA, Koski TR, et al. Impact of CrossFit-related spinal injuries. Clin J Sport Med. 2017;1-4; doi: 10.1097/JSM.0000000000000553.

87. Keogh JW, Winwood PW. The epidemiology of injuries across the weight-training sports. Sports Med. 2017;47(3): 479-501; doi: 10.1007/s40279-016-0575-0.

88. Kliszczewicz B, Buresh R, Bechke E, Williamson C. Metabolic biomarkers following a short and long bout of high-intensity functional training in recreationally trained men. J Hum Sport Exerc. 2017;12(3):710-718; doi: 10.14198/jhse.2017.123.15.

89. Maté-Muñoz JL, Lougedo JH, Barba M, García-Fernández P, Garnacho-Castaño MV, Domínguez R. Muscular fatigue in response to different modalities of CrossFit sessions. PLoS One. 2017;12(7):e0181855; doi: 10.1371/ journal.pone.0181855.

90. Maxwell C, Ruth K, Friesen C. Sports nutrition knowledge, perceptions, resources, and advice given by certified CrossFit trainers. Sports. 2017;5(2):21; doi: 10.3390/ sports5020021.

91. Mehrab M, de Vos RJ, Kraan GA, Mathijssen NMC. Injury incidence and patterns among Dutch CrossFit athletes. Orthop J Sports Med. 2017;5(12):23259671 17745263; doi: 10.1177/2325967117745263.

92. Meyer J, Morrison J, Zuniga J. The benefits and risks of CrossFit: a systematic review. Workplace Health Saf. 2017;65(12):612-618; doi: 10.1177/2165079916685568.

93. Montalvo AM, Shaefer H, Rodriguez B, Li T, Epnere K, Myer GD. Retrospective injury epidemiology and risk factors for injury in CrossFit. J Sports Sci Med. 2017; 16(1):53-59.

94. Moran S, Booker H, Staines J, Williams S. Rates and risk factors of injury in CrossFit ${ }^{\mathrm{TM}}$ : a prospective cohort study. J Sports Med Phys Fitness. 2017;57(9):11471153; doi: 10.23736/S0022-4707.16.06827-4.

95. Nieuwoudt S, Fealy CE, Foucher JA, Scelsi AR, Malin SK, Pagadala M, et al. Functional high-intensity training improves pancreatic beta-cell function in adults with type 2 diabetes. Am J Physiol Endocrinol Metab. 2017; 313(3):E314-E320; doi: 10.1152/ajpendo.00407.2016.

96. Rountree JA, Krings BM, Peterson TJ, Thigpen AG, McAllister MJ, Holmes ME, et al. Efficacy of carbohydrate ingestion on CrossFit exercise performance. Sports. 2017;5(3):61; doi: 10.3390/sports5030061.
97. James EP, Gill R. Neoliberalism and the communicative labor of CrossFit. Commun Sport. 2018;6(6): 703-727; doi: 10.1177/2167479517737036.

98. Serafini PR, Feito Y, Mangine GT. Self-reported measures of strength and sport-specific skills distinguish ranking in an international online fitness competition. J Strength Cond Res. 2018;32(12):3474-3484; doi: 10.1519/JSC.0000000000001843.

99. Sibley BA, Bergman SM. What keeps athletes in the gym? Goals, psychological needs, and motivation of CrossFit $^{\mathrm{TM}}$ participants. Int J Sport Exerc Psychol. 2018; 16(5):555-574; doi: 10.1080/1612197X.2017.1280835.

100. Box AG, Feito Y, Petruzzello SJ, Mangine GT. Mood state changes accompanying the CrossFit Open ${ }^{\mathrm{TM}}$ competition in healthy adults. Sports. 2018;6(3); doi: $10.3390 /$ sports6030067.

101. Carnes AJ, Mahoney SE. Polarized vs. high intensity multimodal training in recreational runners. Int J Sports Physiol Perform. 2018;1-28; doi: 10.1123/ ijspp.2018-0040.

102. Cazayoux M, Bishop A, Navalta J, Harris C, Adams K, DeBeliso M. The reliability of the 12-item grit scale among CrossFit participants. Eur J Phys Educ Sport Sci. 2018;4(10); doi: 10.5281/zenodo.1341640.

103. Claudino JG, Gabbett TJ, Bourgeois F, Souza HS, Miranda RC, Mezêncio B, et al. CrossFit overview: systematic review and meta-analysis. Sports Med Open. 2018;4(1):11; doi: 10.1186/s40798-018-0124-5.

104. Crawford DA, Drake NB, Carper MJ, DeBlauw J, Heinrich KM. Validity, reliability, and application of the session-RPE method for quantifying training loads during high intensity functional training. Sports. 2018;6(3); doi: 10.3390/sports6030084.

105. Crawford DA, Drake NB, Carper MJ, DeBlauw J, Heinrich KM. Are changes in physical work capacity induced by high-intensity functional training related to changes in associated physiologic measures? Sports. 2018;6(2); doi: 10.3390/sports6020026.

106. Dilber AO, Doğru Y. The effect of high-intensity functional exercises on anthropometric and physiological characteristics in sedentary. Int J Sport Exerc Train Sci. 4(2):64-69; doi: 10.18826/useeabd.425483.

107. Dominski FH, Siqueira TC, Serafim TT, Andrade A. Injury profile in CrossFit practitioners: systematic review. Fisioter Pesqui. 2018;25(2):229-239; doi: 10.1590/ 1809-2950/17014825022018.

108. Durkalec-Michalski K, Zawieja EE, Podgórski T, Łoniewski I, Zawieja BE, Warzybok M, et al. The effect of chronic progressive-dose sodium bicarbonate ingestion on CrossFit-like performance: a double-blind, randomized cross-over trial. PLoS One. 2018;13(5): e0197480; doi: 10.1371/journal.pone.0197480.

109. Feito Y, Burrows EK, Tabb LP. A 4-year analysis of the incidence of injuries among CrossFit-trained participants. Orthop J Sports Med. 2018;6(10):2325 967118803100; doi: 10.1177/2325967118803100.

110. Feito Y, Moriarty TA, Mangine G, Monahan J. The use of a smart-textile garment during high-intensity func- 
tional training. A pilot study. J Sports Med Phys Fitness. 2018; doi: 10.23736/S0022-4707.18.08689-9.

111. Feito Y, Hoffstetter W, Serafini P, Mangine G. Changes in body composition, bone metabolism, strength, and skill-specific performance resulting from 16-weeks ofHIFT. PLoS One. 2018;13(6):e0198324; doi: 10.1371/ journal.pone.0198324.

112. Feito Y, Brown C, Box A, Heinrich KM, Petruzzello SJ. An investigation into how motivational factors differed among individuals engaging in CrossFit training. SAGE Open. 2018;8(3); doi: 10.1177/21582440188 03139.

113. Gephart LF, Doersch KM, Reyes M, Kuehl TJ, Danford JM. Intraabdominal pressure in women during CrossFit exercises and the effect of age and parity. Proc (Bayl Univ Med Cent). 2018;31(3):289-293; doi: 10.1080/08998280.2018.1446888.

114. Gipson C, Campbell N, Malcom NL. Partnerships between an at-risk youth CrossFit program and local community organizations: focusing on the antecedents to partnership development. Sports. 2018;6(3); doi: $10.3390 /$ sports6030100.

115. Kephart WC, Pledge CD, Roberson PA, Mumford PW, Romero MA, Mobley CB, et al. The three-month effects of a ketogenic diet on body composition, blood parameters, and performance metrics in CrossFit trainees: a pilot study. Sports. 2018;6(1):1; doi: 10.3390/sports 6010001.

116. Klimek C, Ashbeck C, Brook AJ, Durall C. Are injuries more common with CrossFit training than other forms of exercise? J Sport Rehab. 2018;27(3):295-299; doi: 10.1123/jsr.2016-0040.

117. Kliszczewicz B, Williamson C, Bechke E, McKenzie M, Hoffstetter W. Autonomic response to a short and long bout of high-intensity functional training. J Sports Sci. 2018;36(16):1872-1879; doi: 10.1080/02640414. 2018.1423857.

118. Mangine GT, Cebulla B, Feito Y. Normative values for self-reported benchmark workout scores in CrossFit ${ }^{\circledR}$ practitioners. Sports Med Open. 2018;39; doi: 10.1186/ s40798-018-0156-x.

119. Mangine GT, Van Dusseldorp TA, Feito Y, Holmes AJ, Serafini PR, Box AG, et al. Testosterone and cortisol responses to five high-intensity functional training competition workouts in recreationally active adults. Sports. 2018;6(3); doi: 10.3390/sports6030062.

120. Podmore M, Ogle JP. The lived experience of CrossFit as a context for the development of women's body image and appearance management practices. Fash Text. 2018;5(1):1; doi: 10.1186/s40691-017-0116-y.

121. Prewitt-White T, Connolly CP, Feito Y, Bladek A, Forsythe S, Hamel L, et al. Breaking barriers: women's experiences of CrossFit training during pregnancy. Women Sport Phys Act J. 2018;26(1):33-42; doi: 10.1123/wspaj.2017-0024.

122. Schubert MM, Palumbo EA. Energy balance dynamics during short-term high-intensity functional training.
Appl Physiol Nutr Metab. 2019;44(2):172-178; doi: 10.1139/apnm-2018-0311.

123. Sławińska M, Stolarski M, Jankowski KS. Effects of chronotype and time of day on mood responses to CrossFit training. Chronobiol Int. 2019;36(2):237249; doi: 10.1080/07420528.2018.1531016.

124. Tibana RA, de Sousa NMF. Are extreme conditioning programmes effective and safe? A narrative review of high intensity functional training methods research paradigms and findings. BMJ Open Sport Exerc Med. 2018;4(1):e000435; doi:10.1136/bmjsem-2018-000435.

125. Cornwall W. Crossing swords with CrossFit. Outside. 2013. Available from: https://www.outsideonline. com/1928106/crossing-swords-crossfit.

126. Han AP. Journal retracts Ohio state CrossFit study at center of lawsuits. Retraction Watch. 2017. Available from: http://retractionwatch.com/2017/06/02/journalretracts-ohio-state-crossfit-study-center-lawsuits/.

127. Han AP. Researcher who tangled with CrossFit loses two more papers. Retraction Watch. 2017. Available from: http://retractionwatch.com/2017/06/30/researcher-tangled-crossfit-loses-two-papers/\#more50890.

128. Sperandei S, Vieira MC, Reis AC. Adherence to physical activity in an unsupervised setting: explanatory variables for high attrition rates among fitness center members. J Sci Med Sport. 2016;19(11):916-920; doi: 10.1016/j.jsams.2015.12.522.

129. 2018 Physical Activity Guidelines Advisory Committee. 2018 Physical Activity Guidelines Advisory Committee Scientific Report. Washington, DC: U.S. Department of Health and Human Services; 2008.

130. World Health Organization. Global strategy on diet, physical activity and health. Available from: http:// www.who.int/dietphysicalactivity/pa/en/.

131. Macfarlane B. Researching with integrity: the ethics of academic enquiry. New York: Routledge; 2010.

132. Gerteis J, Izrael D, Deitz D, LeRoy L, Ricciardi R, Miller T, et al. Multiple chronic conditions chartbook. AHRQ Publications No, Q14-0038. Rockville: Agency for Healthcare Research and Quality; 2014.

133. American College of Sports Medicine. General principles of exercise prescription. In: Riebe D (ed.). ACSM's guidelines for exercise testing and prescription, $10^{\text {th }} \mathrm{ed}$. Philadelphia: Lippincott Williams \& Wilkins; 2017; 143-179. 